\title{
ENSINO COM PESQUiSA E JÚRI SIMULADO COMO ESTRATÉGIAS DE ENSINO PARA DISCUTIR A EDUCAÇÃo ESCOLAR INDÍGENA
}

\author{
TEACHING WITH RESEARCH AND SIMULATED JURY AS STRATEGIES OF \\ INSTRUCTION IN ORDER TO DISCUSS ON INDIGENOUS SCHOOL EDUCATION
}

DOI: http://dx.doi.org/10.23926/RPD.2526-2149.2018.v3.n2.p752-767.id221

\section{Marinete Moura da Silva Lobo \\ Mestranda em Ensino pela Universidade Vale do Rio dos Sinos - RS \\ marinete.lobo@universo.uni vates.br}

\section{José Claudio Del Pino \\ Doutor em Engenharia de \\ Biomassa (UFRGS) \\ jose.pino@univates.br}

\section{Marli Teresinha Quartieri}

Doutora em Educação pela Universidade Vale do Rio dos Sinos - RS marli.quartieri@univates.co $\mathrm{m}$

\section{Miriam Ines Marchi}

Doutora em Química

(UFSM)

mimarchi@univates.br
Resumo: As estratégias de ensino podem contribuir para uma aprendizagem significativa, ao mesmo tempo em que contribuem para a motivação intrínseca do aluno. Entre as várias estratégias de ensino, destacam-se, neste trabalho, o "ensino com pesquisa" e o "júri simulado" como procedimentos metodológicos para discutir a Educação Escolar Indígena na disciplina Educação Indígena, do $5^{\circ}$ período do curso de Pedagogia de uma Instituição de Educação Superior na cidade de Barra do Corda - MA. Trata-se de um relato de experiência da aplicação das estratégias de ensino citadas para discutir questões pertinentes à educação escolar ofertadas nas comunidades indígenas. A relevância do tema escolhido se dá em razão desta região central do Estado do Maranhão apresentar um grande contingente populacional indígena das etnias Canela (Ramkokamekrá e Apaniekrá) e TeneteharaGuajajara. As estratégias de ensino com pesquisa e júri simulado oportunizaram atividades desafiadoras para construir atitudes científicas e pedagógicas necessárias à compreensão do assunto investigado e discutido.

Palavras-chave: Estratégia de ensino. Júri simulado. Ensino com pesquisa. Educação Escolar Indígena. RCNEI/Indígena.

\begin{abstract}
Teaching strategies may contribute to an effective instruction as well as to an intrinsic motivation of the student learning. Among the several teaching strategies, they are highlighted, in this paper, the "teaching with research" and the "mimic jury" as methodological procedures to discuss the indigenous school education, based on a school subject of the 5th school term, performed by a teacher education undergraduate course (named Pedagogy) in a local College in Barra do Corda - MA - Brazil. This is an experience report with its application that involves both strategies mentioned, to discuss issues which are relevant to the school education which is offered to the indigenous communities. Bearing in mind the enormous importance of the chosen theme, mainly because of the central region of the state of Maranhão that presents a large contingent indigenous population whose descendants are from the ethnic groups Canela (Ramkokamekrá and Apaniekrá) and Tenetehara-Guajajara. The strategies "teaching with research" and "mimic jury" have provided challenging activities to develop scientific and pedagogical atitudes necessary to understand the subject investigated and discussed.
\end{abstract}

Keywords: teaching strategy. Mimic jury. Teaching with research. Indigenous school education. RCNEI/indigenous. 


\section{INTRODUÇÃO}

Este artigo tem por objetivo descrever a utilização das estratégias de ensinoaprendizagem "júri simulado" e "ensino com pesquisa", numa turma de Pedagogia para discutir a temática da educação escolar indígena.

As dinâmicas de grupo possuem um caráter motivacional e construtivo, podendo ser utilizadas como propostas pedagógicas na perspectiva de auxiliar o desenvolvimento do ensino em qualquer disciplina. São capazes de promover aprendizagens significativas, tomando como ponto de partida a motivação para aprender.

Dessa forma, destaca-se que o uso de diferentes estratégias de ensino é imprescindível em todos os níveis de ensino para despertar o interesse dos alunos a fim de que possam construir um conhecimento significativo. Entre essas estratégias destacam-se, neste trabalho, o ensino com pesquisa e o júri simulado, que foram escolhidas para a aplicação prática em sala de aula e, em seguida, para elaboração de um relato da experiência. A aplicação foi realizada em uma turma do $5^{\circ}$ Período do Curso de Pedagogia de uma instituição superior da rede privada, onde se trabalhou a disciplina Educação Indígena.

O objetivo da utilização das estratégias de ensino trabalhadas foi discutir a Educação Escolar Indígena à luz dos Referenciais Curriculares Nacionais para as Escolas Indígenas (BRASIL, 1998), bem como, de forma mais específica, compreender os conceitos de educação intercultural e bilíngue e também relacionar os maiores desafios para a efetivação de uma educação indígena específica e diferenciada.

Justifica-se a utilização das estratégias de ensino denominadas ensino com pesquisa e júri simulado para trabalhar a disciplina Educação Indígena em razão da necessidade de dinamizar os conteúdos constantes na ementa. O objetivo foi envolver diretamente os alunos para que, de forma interativa, construíssem os conhecimentos a partir das atividades desafiadoras que foram a eles propostas ao trabalhar com as citadas estratégias de ensino.

Quando se definiu a utilização da estratégia ensino com pesquisa, buscou-se desafiar os alunos para assumirem uma postura investigativa. Ao problematizar, tiveram a oportunidade de aprender a aprender e participar ativamente do estudo. $\mathrm{O}$ ensino com pesquisa também possibilita ao aluno passar da simples reprodução do conhecimento para um equilíbrio entre reprodução e análise (ANASTASIOU; ALVES, 2004, p. 68).

Ressalta-se que a primeira estratégia definida para ser utilizada foi a do júri simulado, contudo, como já havia a determinação que fossem utilizadas duas estratégias de ensino para a aplicação em sala de aula, buscou-se uma outra que interagisse com a estratégia já definida, 
chegando-se à conclusão de que a estratégia ensino com pesquisa seria a mais adequada e, inclusive, serviria para fundamentar o júri simulado.

Assim, primeiramente, foi utilizada a estratégia ensino com pesquisa durante quatro semanas e, em seguida, foi realizada a estratégia júri simulado, tendo duas semanas para a organização e um dia para a apresentação.

\section{REFERENCIAL TEÓRICO}

As estratégias de ensino são um ato de escolha da prática docente. Nesse ato, ao optar por trabalhar conteúdos através delas, o professor possibilita que o aluno compreenda os fatos e não apenas os memorize. Cada estratégia de ensino deve ser selecionada em função dos objetivos a serem alcançados e dos conteúdos a serem desenvolvidos, considerando o alunado com que se está trabalhando.

Lemov (2011, p. 66) evidencia a importância de o professor desenvolver seus conteúdos a partir de diferentes abordagens. Para ele, tudo em uma escola deve estar a serviço do aprendizado do aluno. Por isso, todas as técnicas utilizadas em sala de aula devem estar direcionadas para promover o desenvolvimento cognitivo, aprimorar habilidades, compreender conteúdos. Volta-se também para a preocupação com o tempo, uma vez que "cada minuto perdido é uma preocupação com o aluno, pois é um minuto a menos de aprendizagem”.

Carlini (2004) afirma que o ensino com pesquisa é muito mais que determinar que os alunos façam pesquisas, caracterizadas pela busca bibliográfica impressa ou virtual das informações pretendidas. É uma atividade de ensino que demanda tempo e dedicação dos envolvidos na produção de conhecimentos. A autora ainda salienta que:

\section{[...] o ensino com pesquisa é uma situação de aprendizagem na qual o aluno realiza transformações de ordem conceitual (coleta, seleciona, organiza, relaciona e registra informações), procedimental (observação, manuseio das fontes e documentos diversos, utilização de diferentes ambientes educativos, registro e expressão oral) e atitudinal (cooperação e autoconfiança) (CARLINI, 2004, p. 38).}

Utilizar a estratégia de ensino com pesquisa requer, além de tempo e dedicação, muita paciência do professor. Acompanhar o processo de ensino com pesquisa possibilita, pela situação individual ou de pequenos grupos, identificar suas facilidades e dificuldades e reorientar a aprendizagem sempre que houver necessidade.

Entre as atribuições do professor na utilização da estratégia ensino com pesquisa, segundo Carlini (2004, p. 40), estão a orientação clara aos alunos quanto à escolha do tema e dos objetivos da investigação; a formação de subgrupos de pesquisa quando a turma for 
numerosa, delegando a cada um deles um aspecto da investigação, como um desdobramento do problema da pesquisa e a descrição de um plano de pesquisa contendo o detalhamento das ações a serem realizadas.

Por outro lado, o aluno também possui grandes atribuições e responsabilidades na estratégia ensino com pesquisa, entre as quais, Carlini (2004) menciona a busca das informações necessárias à investigação, selecionando e organizando o material necessário; a elaboração de relatório final em cooperação com os demais participantes do grupo e a apresentação de síntese das principais ideias da investigação.

A construção do processo de investigação e o desenvolvimento de competências de pesquisa são tão ou mais importantes do que os resultados alcançados.

A dinâmica do ensino com pesquisa é desafiar o aluno como investigador e construtor de projetos, estabelecendo princípios de movimento e alteração de conhecimento, de solução de problemas, de critérios de validação, reprodução e análise. Uma aprendizagem significativa onde o aluno, ao problematizar, aprende a aprender. E participa ativamente do ensino (RODRIGUES; GONÇALVES, 2013, p. 243).

De acordo com Rodrigues e Gonçalves (2013), existem bons resultados em experiências de combinação do ensino com pesquisa com outras estratégias de ensino e aprendizagem. Entre elas, destacam-se: aprendizagem por projetos, simulações, laboratório/wokshop e júri simulado.

O júri simulado como uma das possibilidades de ensino-aprendizagem desafia o aluno a inúmeras ações: a defesa de ideias, o poder de argumentação, o julgamento, a tomada de decisão, dentre outras (ANASTASIOU; ALVES, 2004). É uma estratégia que proporciona um maior envolvimento e participação dos alunos na sala de aula, gerando uma mobilização em relação ao conteúdo em questão. $\mathrm{O}$ júri simulado contribui significativamente para o desenvolvimento da argumentação no aluno.

Com a prática do júri simulado, “a expressão verbal do aluno é desenvolvida diante de todos os colegas, levando a se exporem às habituais críticas dos outros" (ANASTASIOU; ALVES, 2004, p. 7). Nesse sentido, é preciso entender que:

[...] o esquema textual evocado para a construção do discurso argumentativo requer do sujeito a capacidade de relacionar e articular argumentos e posição, por semelhanças ou diferenças, à medida em que constrói conceptualizações, generalizações e abstrações sobre um dado tema polêmico sobre o qual deve emitir sua opinião (BARROSO, 2007, p. 102).

Real e Meneses (2007, p. 96) também ressaltam a importância do júri simulado em sala de aula por ser uma prática que estimula a "reflexão dialogada, o pensamento crítico, a exposição e o respeito às diferenças e a tomada de posição a partir de argumentos mais sólidos". 
Diante das considerações supracitadas, ressalta-se que o júri simulado é uma valiosa ferramenta didática da qual o professor, em diferentes disciplinas, pode lançar mão. É o que se comprova neste relato de experiências.

\section{APLiCANDO AS ESTRATÉGIAS DE ENSINO NA PRÁTICA DOCENTE}

Conforme Souza (2010), as estratégias de ensino atendem ao desenvolvimento cognitivo do educando e contribuem para a construção da dimensão afetivo-emocional no desempenho escolar, porque exigem do estudante um papel ativo na elaboração do conhecimento.

Nesse sentido, a estratégia de ensino-aprendizagem contribui para a construção de uma postura ativa do estudante. Souza (2010) ainda enfatiza variados recursos que são usados pelos estudantes para aprender uma nova matéria ou adquirir determinadas habilidades, que segundo ele, possibilita verificar uma gama ampla de ações e muitas maneiras de classificar as estratégias de aprendizagem.

Dessa forma, é necessário inovar metodologias e monitorar a busca por melhores desempenhos do alunado em suas atividades escolares, e foi com este intuito que se vivencious a experiência de discutir a temática "educação escolar indígena" através de duas estratégias de ensino e aprendizagem "pesquisa com ensino" e "júri simulado".

\subsection{ENSINO COM PESQUISA}

A estratégia ensino com pesquisa foi desenvolvida em uma turma de $5^{\circ}$ período do curso de Pedagogia de uma instituição superior da rede privada. Fez-se uma fala inicial explicando o passo a passo dessa estratégia de ensino, bem como os objetivos a serem alcançados por meio do estudo dos conteúdos, entre os quais se destacaram o desenvolvimento do sentimento de autoconfiança, a capacidade de elaboração de síntese e a comunicação clara dos resultados a serem obtidos na realização da pesquisa.

A turma de Pedagogia na qual a estratégia citada foi realizada continha vinte e quatro alunos. Assim, foi necessário trabalhar com quatro grupos de seis componentes. Na sequência, foi definido que se iniciaria pela pesquisa bibliográfica sobre o tema geral "Educação Escolar Indígena", com base no Referencial Curricular Nacional para as Escolas Indígenas (BRASIL, 1998), dividido em subtemas que foram distribuídos para os grupos constituídos, ficando delineado desta forma: $1^{\circ}$ grupo - Fundamentos Gerais da Educação Escolar Indígena; $2^{\circ}$ grupo - Ajudando a construir currículos nas escolas indígenas; $3^{\circ}$ grupo - Temas transversais nas escolas indígenas; $4^{\circ}$ grupo - $\mathrm{O}$ bilinguismo nas escolas indígenas. 
Considerando que não basta determinar que o aluno faça a pesquisa e que o professor deva orientar e acompanhar todo seu desenvolvimento, cumpriu-se o seguinte passo a passo de orientações:

$1^{\circ}$ passo - Coleta de material - com base em Demo (1996), a procura de material é um início instigador e contribui para o estudante não se acomodar a receber tudo pronto. Orientouse, então, a pesquisarem os temas no RCNE/Indígena e também em outras bibliografias complementares.

$2^{\circ}$ passo - Motivação para as interpretações/o desafio da elaboração própria - explicouse aos alunos que eles poderiam interpretar os textos referentes à temática com um certo grau de autonomia, bem como poderiam construir e reconstruir os textos estudados. Após dividir os subtemas e distribuir para os grupos, discutiu-se e ilustrou-se os conceitos intrínsecos às etapas de planejamento e execução da pesquisa.

$3^{\circ}$ passo - Sequencialmente, identificou-se as principais dúvidas e dificuldades de caráter técnico, teórico e metodológico dos alunos e promoveu-se discussões, explicações com exemplificações.

$4^{\circ}$ passo - Agendou-se momentos diferenciados para atendimento dos grupos de forma pontual, considerando a especificidade de cada tema/problema investigado e o estágio em que cada grupo se encontrava no desenvolvimento da pesquisa.

$5^{\circ}$ passo - Houve um encontro exclusivo para a elaboração do instrumento de coleta de informações, que foi definido como questionário-entrevista para todos os grupos. Cada grupo elaborou seu instrumento com base no tema definido para a equipe.

O primeiro grupo realizou somente pesquisa bibliográfica, fazendo um levantamento histórico e da legislação Educação Escolar Indígena. O segundo grupo fez uma pesquisa sobre o currículo da escola indígena como orienta o RCNE/Indígena, realizando entrevista com professores que trabalham nas comunidades indígenas. Com base nas respostas desses professores, observou-se que o currículo trabalhado nas escolas indígenas não se diferencia do currículo trabalhado nas escolas não indígenas.

O terceiro grupo fez uma pesquisa sobre os temas transversais nas escolas indígenas. Foi realizada, inicialmente, uma pesquisa bibliográfica sobre esses temas no currículo indígena conforme as orientações do RCNE/Indígena que define os temas transversais específicos para a educação indígena: Terra e Conservação da Biodiversidade; Autossustentação; Direito, Lutas e Movimentos; Pluralidade Cultural e Saúde e Educação. Depois da pesquisa bibliográfica, os graduandos realizaram entrevistas com professores que trabalham em escolas indígenas 
localizadas nas proximidades do município de Barra do Corda - MA, efetuando assim a pesquisa de campo. Uma das s inferências que emergiu da análise dos resultados da pesquisa de campo é que no currículo da escola indígena não são trabalhados os temas transversais orientados pelo RCNE/Indígena.

O quarto grupo pesquisou o bilinguismo nas escolas indígenas. Inicialmente, realizaram uma pesquisa bibliográfica sobre as concepções e o tratamento legal que é dispensado ao ensino da língua materna e da língua oficial brasileira nas escolas indígenas. Na sequência, o grupo fez a pesquisa de campo entrevistando quatro professores indígenas e três professores não indígenas que trabalham em comunidades indígenas. A análise dos resultados permitiu inferir que a língua materna só é trabalhada na Educação Infantil e nos anos iniciais do Ensino Fundamental, juntamente com a Língua Portuguesa. Assim, o bilinguismo só acontece da educação infantil até o quinto ano do Ensino Fundamental. A partir do sexto ano, os conteúdos são trabalhados somente na língua oficial brasileira.

Em síntese, realizou-se as seguintes atividades na aplicação da estratégia ensino com pesquisa: revisão da literatura indicada, desenvolvimento e aplicação de uma entrevista semiestruturada com quatro professores indígenas e três professores não indígenas que trabalham em aldeias, acerca da temática pesquisada em cada grupo; organização das respostas às entrevistas a partir de critérios definidos pelos grupos; as informações coletadas foram analisadas quali-quantitativamente em sala de aula; apresentação oral dos resultados pelos grupos e redação dos resultados da pesquisa.

\subsection{JÚRI Simulado}

A estratégia de ensino júri simulado apresenta-se com o formato de uma sessão do tribunal de júri, com algumas adaptações para o desenvolvimento enquanto atividade pedagógica de forma que favoreça o entendimento dos alunos.

O tema definido para o trabalho com o júri simulado decorreu dos temas utilizados quando se trabalhou com a estratégia ensino com pesquisa. Os grupos pesquisaram: Os fundamentos gerais da educação escolar indígena; Ajudando a construir currículos nas escolas indígenas; Temas transversais nas escolas indígenas e $\mathrm{O}$ bilinguismo nas escolas indígenas.

Os resultados obtidos, que foram apresentados pelos grupos, culminaram na afirmação de que se tem uma escola de "branco" transportada para o universo indígena. Assim, definiuse o tema do júri simulado: "A educação para índios no banco dos réus". 
Para a realização do júri simulado, dividiu-se a turma da seguinte forma: Promotoria: grupo composto por seis alunos com a missão de provar que a escola de branco transportada para o mundo dos índios só traz malefícios para as comunidades indígenas. Defesa: grupo formado por seis alunos com a missão de buscar elementos que justifiquem a necessidade de uma escola nos moldes do "branco" no universo indígena, para que esse povo tenha a mesma educação que é ofertada para os não indígenas a fim de que possam ter uma relação menos desigual com a sociedade dominante. Jurados: sete alunos incumbidos de prestar atenção nos argumentos levantados pela defesa e pela promotoria para, ao final, deliberar a sentença acerca dos malefícios ou benefícios da escola de branco no universo indígena. Testemunhas: quatro alunos que desempenharam o papel de testemunhas, sendo que estariam à disposição da Defesa e da Promotoria, as quais poderiam usá-las como prova testemunhal. Esses quatro alunos representavam personagens relacionados à escola indígena: uma professora de escola indígena, uma liderança indígena, uma supervisora do órgão regional de educação responsável pelo acompanhamento pedagógico das escolas indígenas e um aluno indígena. Juiz: responsável pela organização da sessão do júri. Um aluno foi selecionado para desempenhar essa função.

Todas as funções acima descritas foram definidas através de sorteio.

\subsubsection{O TEMA EM JULGAMENTO: A ESCOLA PARA ÍNDIOS NO BANCO DOS RÉUS}

Os resultados das pesquisas realizadas através das estratégias anteriormente desenvolvidas possibilitaram inferir que o que se tem na prática é uma escola de "brancos" transportada para as comunidades indígenas, ou seja, não se tem efetivamente uma educação escolar indígena, mas uma educação escolar no mesmo formato das escolas não indígenas, ofertadas nas aldeias.

Assim, o que se vê nas comunidades indígenas é uma escola que possui uma infraestrutura precária, sem os equipamentos básicos e boa parte delas sem um prédio próprio. Realidade que não se diferencia das escolas não indígenas localizadas na zona rural de Barra do Corda - MA. Ademais, o currículo trabalhado nas escolas indígenas é o mesmo das escolas não indígenas, com o diferencial de que na Educação Infantil e nos anos iniciais do Ensino Fundamental existe uma disciplina voltada para o ensino da língua materna.

Os professores indígenas entrevistados, pelos acadêmicos, quando trabalhavam conteúdos sobre a educação escolar indígena, através da estratégia ensino com pesquisa, responderam que querem que a escola da aldeia trabalhe os conteúdos que são ensinados nas escolas dos "brancos", porque querem aprender esses conhecimentos para se sentirem em 
situação de igualdade com a sociedade envolvente, contudo, querem que a cultura indígena também seja trabalhada na escola.

Através da escola, os professores entrevistados (indígenas e não indígenas) afirmam que seus alunos esperam estar preparados para terem as mesmas oportunidades de prosseguimento de estudos ou de inserção no mundo do trabalho. Mas essa educação que está sendo ofertada realmente atende aos interesses e às demandas indígenas? Em que medida essa educação está sendo benéfica ou maléfica para essas comunidades?

\subsubsection{Argumentos Utilizados PELA PROMOTORIA}

A equipe da promotoria utilizou argumentos baseados na legislação educacional que normatiza e regulamenta a educação escolar indígena, partindo da Constituição Federal, em seu Art.210, que assegura às comunidades indígenas, no Ensino Fundamental regular, o uso de suas línguas maternas e processos próprios de aprendizagem e garante a prática do ensino bilíngue em suas escolas (BRASIL, 1988).

Em seguida, mencionaram o Decreto Presidencial no 26/1991 (BRASIL, 1991), que transferiu a responsabilidade pela educação escolar indígena da Fundação Nacional do Índio (FUNAI) para o Ministério da Educação e este para as Secretarias de Estado da Educação, passando a incumbência de integrar a educação escolar indígena aos sistemas de ensino regular, bem como coordenar as ações referentes a essas escolas em todos os níveis de ensino.

A Lei de Diretrizes e Bases da Educação Nacional (LDB), Lei n 9394/96, em seu Art. 79, determina que deve haver apoio técnico e financeiro para o provimento da educação escolar indígena, afirmando que os programas educacionais deverão ser planejados com a participação das comunidades indígenas. Os direitos estabelecidos na LDB e nas legislações subsequentes enfatizam que a educação escolar indígena deverá ter um tratamento diferenciado, determinado pela prática da interculturalidade e do bilinguismo (BRASIL, 1996). A equipe da promotoria ressaltou que todos esses preceitos estão distantes de serem efetivados.

A promotoria utilizou também como argumento o RCNEI/Indígena que orienta como deve ser a escola indígena e a caracteriza como comunitária, bilíngue/multilíngue, específica e diferenciada. Enfatizou-se, ainda, que a pesquisa realizada anteriormente permitiu inferir a existência de uma grande lacuna para a efetivação das orientações curriculares do RCNEI/Indígena e dos documentos oficiais.

Conforme Candado (2006), para acontecer a relação ideal entre o que se propõe nos documentos oficiais e o que efetivamente é praticado, é necessário que o processo educacional 
realizado nas escolas indígenas seja reestruturado desde a formação dos profissionais, passando pela elaboração de um currículo que atenda aos anseios dessas comunidades e por sua aplicação concreta nas práticas escolares. A promotoria argumentou de forma bastante enfática que, infelizmente, não é o que acontece na educação escolar que é oferecida aos indígenas.

A acusação mencionou, ainda, a Convenção 169 da Organização Internacional do Trabalho (OIT) (BRASIL, 2004), que se traduz num instrumento para a inclusão social dos povos indígenas, e o Decreto Presidencial no 5051/2004 (BRASIL, 2004), o qual determina que a citada convenção seja inteiramente executada e cumprida no Brasil.

O grupo de acusação finalizou dizendo que a educação escolar indígena, almejada por muitos povos indígenas que veem na educação um instrumento de luta e valorização de sua cultura, ficou só no nível de legislação, pois todos os avanços conquistados ficaram apenas nos textos legais e que, de fato, o que é ofertado para as comunidades indígenas é uma educação precária que não valoriza as especificidades da cultura indígena. A Promotoria pediu, então, que os jurados condenassem a escola que é ofertada a essas comunidades e, consequentemente, o poder público que a oferece, neste caso, o poder público estadual.

\subsubsection{DEPOIMENTOS DAS TESTEMUNHAS}

Professora indígena: a escola da aldeia não tem equipamentos, nem acompanhamento pedagógico. A merenda escolar é insuficiente e não há sequer o material básico para o trabalho pedagógico.

Liderança indígena: o Estado não contrata o número necessário de professores para o atendimento dos alunos que estudam nas aldeias. Também não há contratação dos profissionais de apoio, como auxiliar de serviços gerais, administrativos e coordenadores pedagógicos.

Supervisora do órgão regional de educação: os professores indígenas e não índios que trabalham na escola indígena não cumprem horários, não trabalham de segunda a sexta-feira, não fazem registros do processo pedagógico.

Aluno indígena: queremos que nossa escola seja igual às escolas que estão na cidade. Os brancos chegaram aqui há mais de quinhentos anos e nos deram uma educação de acordo com os conhecimentos deles. Hoje nós queremos uma escola que seja igual à do branco, mas que também valorize a nossa cultura.

\subsection{ARGUMENTOS UTILIZADOS PELA DEFESA}

A defesa utilizou o argumento de que a Constituição Federal e a LDB, lei no 9394/1996, trouxeram avanços, "rompendo com uma tradição de quase cinco séculos de política 
integracionista" (OLIVEIRA; FREIRE, 2006, p. 96), contudo, entregaram o gerenciamento dessas políticas para os estados e municípios, sem que se criassem mecanismos para assegurar a implementação desses avanços. Alegou, ainda, que a complexidade da educação indígena envolve situações que vão além dos aspectos legais, sendo necessário um resgate histórico e cultural da educação escolar indígena que, desde os primórdios da colonização brasileira, tem sido alheia ao que deveria ser suas reais finalidades. A defesa argumentou também que a mudança desse paradigma não pode ser realizada em um curto prazo de tempo.

Nesse sentido, Araújo et al. (2006) dividem a educação indígena no Brasil em quatro fases, que foram utilizadas pela equipe de defesa para afirmar que os problemas da educação indígena possuem raízes históricas, como seguem: a primeira fase foi quando o processo de escolarização indígena esteve nas mãos dos missionários jesuítas; na segunda, a responsabilidade era dos órgãos assistencialistas, primeiramente do Serviço de Proteção ao Índio (SPI) e depois da FUNAI; na terceira fase, que começa na década de sessenta, entram em cena as organizações não-governamentais, como o Conselho Indigenista Missionário (CIMI), a Operação Amazônia Nativa (OPAN), o Centro de Trabalho Indigenista (CTI), a Comissão Pró-índio, entre outras, e a quarta fase, que teve início recentemente, a partir de meados dos anos oitenta, sendo caracterizada pelas reivindicações indígenas para assumir o protagonismo da autogestão dos processos formais de educação em suas comunidades. A partir dos movimentos indígenas e referendada pela Constituição, a educação escolar indígena passou a sofrer profundas transformações.

A equipe de defesa argumentou então que apenas em tempos recentes iniciaram-se as discussões por essa escola indígena, ou seja, a escola pensada a partir da promulgação da Constituição tem como objetivo romper com a dominação e passa a ser um instrumento de reafirmação étnica e cultural, contudo, a efetivação dessas mudanças na prática da educação indígena não se fará a curto prazo. Esse fato, enfatizou a defesa, não é uma prerrogativa só da educação indígena, essa falta de efetividade está na educação brasileira de um modo geral.

Outro argumento utilizado foi o de que os próprios indígenas optam que a escola trabalhe os mesmos conhecimentos que a escola não indígena, pois eles favorecem a aprendizagem de forma que possam conviver com os "brancos" de forma menos desigual. A defesa também utilizou a abordagem de que o próprio processo de aculturação ocasionado pelo contato entre índios e não índios faz com que eles queiram uma escola de brancos para se sentirem no mesmo patamar de formação e de oportunidades. 
Para a defesa, da forma enfática como se pronunciaram, o problema da educação escolar indígena não está dissociado do problema da educação de modo geral. O problema se insere no contexto maior que é o da educação brasileira e que os indígenas não são menos beneficiados que os não índios que estudam em escolas públicas.

A cultura da aldeia, segundo o grupo de defesa, também contribui para fragilizar a qualidade do ensino que é ofertado na escola indígena. Por exemplo, no dia que os indígenas resolvem pescar, eles simplesmente suprimem o dia letivo. Enfatizaram, também, a falta de compromisso de muitos profissionais da escola indígena, inclusive de muitos professores indígenas e não indígenas que são contratados e efetivamente não trabalham.

Finalizaram pedindo absolvição para a educação para índios, que se traduz na escola de branco transportada para o universo indígena, uma vez que diante das condições atuais é a única possível de ser ofertada para essas comunidades.

\subsubsection{O VEREDITO: A PARTICIPAÇÃo dOS JURADOS}

Após ouvir os argumentos da promotoria e os da defesa, bem como os depoimentos das testemunhas, o corpo de jurados votou de forma muito dividida, quatro dos jurados votaram a favor dos argumentos da promotoria e três a favor dos argumentos da defesa.

Em exposição às razões que fundamentaram os jurados que votaram a favor da promotoria, destacou-se o fato de que a legislação educacional que regulamenta a educação escolar indígena deve ser efetivada. Dessa forma, o poder público estadual, por ser a esfera responsável pela oferta de educação escolar indígena, deve ser acionado e responsabilizado para cumprir essa obrigação governamental.

Os jurados que votaram a favor dos argumentos da defesa tomaram por base, principalmente, o depoimento do aluno indígena enfatizou que quer uma escola igual à escola da cidade, pois acredita que esta vai lhe proporcionar uma formação que contribuirá para conquista de seu espaço social, convivendo de forma igualitária com a sociedade não indígena.

\subsubsection{A PARTICIPAÇÃO DO JUIZ}

Considerando as opiniões bem divididas do corpo de jurados, o juiz definiu a sentença fundamentando que, pelas exposições das equipes de promotoria e de defesa, bem como pelo depoimento das testemunhas, a educação para atender aos anseios das comunidades indígenas deve ser uma educação que considere a interculturalidade, isto é, que trabalhe os conhecimentos acumulados pela sociedade envolvente, mas que valorize os processos próprios de aprendizagem dos indígenas, bem como sua língua e cultura tradicionais. Além disso, 
argumentou-se que a esfera estadual, responsável pela educação escolar indígena, deve ser o ente federativo a implementar políticas educacionais interculturais para as comunidades indígenas.

\section{CONSIDERAÇÕES FINAIS}

As duas estratégias de ensino foram bem assimiladas e trabalhadas pelos graduandos do curso de Pedagogia, que avaliaram a aplicação de ambas de forma bastante exitosa. A primeira estratégia utilizada - ensino com pesquisa - fortaleceu, no âmbito da prática educativa, a relação professor-aluno na construção e reconstrução dos conhecimentos para muito além da atitude de serem apenas reprodutores de conhecimentos. Inserida na disciplina Educação Indígena, que é específica do curso de Pedagogia, possibilitou aos alunos que entrassem em contato com o ideal da legislação educacional e o real da prática efetiva da educação escolar indígena.

Por meio do júri simulado, foi possível proporcionar aos graduandos uma reflexão crítica diante do tema educação escolar indígena, estimulando com isso a discussão e o posicionamento dos grupos, ao mesmo tempo favorecendo também a capacidade de argumentação dos participantes. Os resultados deste estudo mostraram que os licenciandos do curso de Pedagogia entenderam e executaram bem a proposta do júri simulado como estratégia de ensino. $\mathrm{O}$ ementário da disciplina de Educação Indígena, integrante da matriz curricular do curso de Pedagogia, trabalhado através das estratégias aplicadas, contribuiu para a ampliação da compreensão da complexidade inerente à educação escolar indígena.

Fez-se uma avaliação sobre a aprendizagem dos alunos a partir das estratégias trabalhadas e os depoimentos foram muito positivos. Questionou-se sobre o que havia sido mais proveitoso no trabalho da temática acerca da educação escolar indígena, trabalhada com as estratégias utilizadas, ao que foram unânimes em responder que as dinâmicas possibilitaram que fizessem a construção e reconstrução de conceitos inseridos na educação escolar indígena, bem como desenvolvessem o senso crítico, a participação e a reflexão.

Pode-se inferir que os objetivos do trabalho dos conteúdos das disciplinas foram alcançados, pois a Educação Escolar Indígena foi discutida de forma dinâmica e à luz dos RCNEI/Indígena. De forma mais específica, os licenciandos em Pedagogia compreenderam conceitos de educação intercultural e bilíngue, assim como também, após terem participado ativamente da construção dos conhecimentos acerca da temática, conseguiram apontar os maiores desafios para a efetivação de uma educação indígena específica e diferenciada. 
A realização das estratégias de ensino com pesquisa e júri simulado mostrou a importância de realizar atividades dinâmicas que envolvem a construção coletiva. Os estudantes perceberam o quanto a investigação científica contribui para uma aprendizagem significativa, conceito central da Teoria de Aprendizagem de Ausubel, na qual o processo de ensino necessita fazer algum sentido para o aluno, e a informação deverá interagir e ancorar-se nos conceitos relevantes já existentes na estrutura cognitiva (MOREIRA, 2003).

Com base nos pressupostos teóricos da aprendizagem significativa, desenvolvidos por Ausubel (Moreira, 2003 p.28) pode-se inferir que a primeira estratégia de ensino utilizada, ensino com pesquisa, teve a função de gerar conhecimentos que serviram de pontos de ancoragem, conhecimentos prévios para os conteúdos que foram trabalhados através da estratégia de ensino júri simulado.

Moreira (2003) também afirma que uma das condições para que ocorra a aprendizagem significativa é a predisposição para aprender. Nesse sentido, as estratégias de ensino utilizadas revelaram que os alunos participantes possuíam essa predisposição porque responderam positivamente quando foram desafiados a trabalhar o conteúdo do ementário da disciplina Educação Indígena através das estratégias ensino com pesquisa e júri simulado.

Ao término desta experiência pedagógica, pode-se observar um maior envolvimento dos estudantes nas discussões, incentivo à pesquisa, trocas de experiências, melhor comunicação, interação dos participantes, ajuda mútua, melhor entendimento sobre a temática estudada, entre tantos outros aspectos. Logo, essa prática de ensino conseguiu transformar a sala de aula de forma muito positiva, pois viabilizou inovação, criatividade, motivação e dinamismo no processo de ensino e aprendizagem.

Assim sendo, podemos afirmar que tanto a estratégia de ensino com pesquisa, como a do júri simulado oferecem suportes para o exercício da autonomia e responsabilidade dos alunos, desafiando-os a construírem atitudes de busca do conhecimento de forma crítica, transformando o processo de ensino e aprendizagem numa atividade prazerosa e significativa.

\section{REFERÊNCIAS}

ANASTASIOU, L. G. C; ALVES, L. P. (Orgs.). Estratégias de Ensinagem. In:. Processos de Ensinagem na Universidade: pressupostos para estratégias de trabalho em aula. 3. ed. Joinville: Univille, 2004. p. 67-100.

ARAÚJO, A. V. et al. Povos Indígenas e as Leis do "Brancos": o direito à diferença. Brasília/Rio de Janeiro: MEC-Secad/Laced, 2006. 
BARROSO, T. O desenvolvimento do discurso argumentativo por crianças do ensino fundamental: articulação e coordenação de sequências argumentativas no texto de opinião. Revista de Estudos Linguísticos Veredas, Juiz de Fora, v. 11, n. 2, 2/2007, p. 101-117.

BRASIL. Constituição (1988). Constituição da República Federativa do Brasil. Disponível em: 〈http://www.planalto.gov.br/ccivil_03/constituicao/constituicao.htm〉. Acesso em: 27 mar. 2018.

BRASIL. Decreto Presidencial nº 26/1991. Dispõe sobre a Educação Indígena no Brasil. Disponível em: <http://www.planalto.gov.br/ccivil_03/decreto/1990-1994/d0026.htm>. Acesso em: 27 mar. 2018.

BRASIL. Lei de Diretrizes e Bases da Educação Nacional. Lei número 9394, 20 de dezembro de 1996. Disponível em: 〈http://www.planalto.gov.br/Ccivil_03/leis/L9394.htm>. Acesso em: 27 mar. 2018.

BRASIL. Ministério da Educação. Referencial Curricular Nacional para as Escolas Indígenas. Brasília: MEC, 1998.

BRASIL. Decreto no 5.051, de 19 de abril de 2004. Promulga a Convenção no 169 da Organização Internacional do Trabalho - OIT sobre Povos Indígenas e Tribais. Disponível em: <http://www.planalto.gov.br/ccivil_03/_ato2004-2006/2004/decreto/d5051.htm>. Acesso em: 27 mar. 2018.

CANDADO, R. A. R. Referencial Curricular Nacional para Escolas Indígenas: Cultura e Conhecimento no Ensino de História. 2006. 111 f. Dissertação (Mestrado em Educação) Universidade Católica Dom Bosco, Campo Grande. Disponível em: <http://site.ucdb.br/public/md-dissertacoes/7923-o-referencial-curricular-nacional-paraescolas-indigenas-cultura-e-conhecimento-no-ensino-de-historia.pdf >. Acesso em: 20 fev. 2018.

CARLINI, A. L. Procedimentos de ensino: escolher e decidir. In: SCARPATO, Marta et al. (Org.). Os procedimentos de ensino fazem a aula acontecer. São Paulo: Avercamp, 2004.

DEMO, P. Educar pela pesquisa. Campinas: Autores Associados, 1996.

LEMOV, D. Aula Nota 10: 49 técnicas para ser um professor campeão de audiência. São Paulo: Da Boa Prosa; Fundação Iemann, 2011.

MOREIRA, M. A. Linguagem e Aprendizagem Significativa. In: ENCONTRO INTERNACIONAL: LINGUAGEM, CULTURA E COGNIÇÃO, 2., 2003, Belo Horizonte. Anais... Belo Horizonte: UFMG, 2003. Disponível em 〈http://www.if.ufrgs.br/ moreira/>. Acesso em: 27 mar. 2018.

OLIVEIRA, J. P.; FREIRE, C. A. R. A Presença Indígena na Formação do Brasil. A presença indígena na formação do Brasil. Brasília: MEC-Secad/Laced, 2006. (Coleção Educação para Todos; 13).

REAL, L. M. C.; MENEZES, C. Júri simulado: possibilidade de construção de conhecimento 
a partir de interações em um grupo. In: NEVADO, R.A.; CARVALHO, M.J.S.; MENEZES, C.S. (Org.). Aprendizagem em rede na Educação a Distância: estudos e recursos para formação de professores. Porto Alegre, RS: Ricardo Lenz, 2007.

RODRIGUES, M.G.V.; GONCALVES, M.D.C. Ensino com Pesquisa: uma estratégia formadora para alunos de pós-graduação em medicina. Rev. Col. Bras. Cir., v. 40, n. 3, p. 241-245, 2013.

SOUZA, L.F.N.I. Estratégias de aprendizagem e fatores motivacionais relacionados. Educar, Curitiba, n. 36, p. 95-107, 2010.

Recebido em: 6 de junho de 2018. Aprovado em: 26 de novembro de 2018. 